\title{
In-situ Lu-Hf and Pu fission track dating of pallasite meteorites
}

\author{
THOMAS BURKE, STIJN GLORIE, MARTIN HAND, \\ ALEXANDER SIMPSON, SARAH GILBERT AND \\ BENJAMIN WADE
}

The University of Adelaide

Presenting Author: thomas.burke@adelaide.edu.au

Pallasites are stony-iron meteorites that are generally accepted to have originated from the core-mantle boundary of a planetesimal. Few pallasite formation ages have been constrained by whole-rock Re-Os and phosphate $\mathrm{Pu}$ fission track dating, which both involve destructive sample preparation and challenging analytical processes (e.g. irradiation at a nuclear facility for fission track dating). Given that only few absolute age determinations exist, it is currently uncertain if the $\sim 130$ pallasite meteorites that have been discovered on Earth were sourced from a single planetary body, or multiple planetoids. We have developed a new analytical workflow using $\mu \mathrm{XRF}$, SEM and LA-ICP-MS/MS that allows in-situ Lu-Hf and Pu fission track dating of phosphate crystals from a polished section of pallasite samples. The main advantages of the approach are: (1) no destructive sample preparation requirements, (2) high spatial resolution and (3) large quantities of data can be collected in a short time span. Fission tracks were analysed using reflective light microscopy and SEM imaging and corrected for contributions from ${ }^{238} \mathrm{U}$ by in-situ measurement of $\mathrm{U}$ concentrations. Cosmic ray tracks were visually distinguished from the fission tracks and discarded to calculate ${ }^{244} \mathrm{Pu}$ fission track ages. Elevated Ytrrium concentrations were detected using $\mu \mathrm{XRF}$ imaging as a proxy for targeting Lu-rich zones in the phosphate grains. Using innovative mass-filtering procedures in an Agilent 8900 reaction-cell mass spectrometer, high order reaction products of ${ }^{176} \mathrm{Hf},{ }^{175} \mathrm{Lu}$ and ${ }^{178} \mathrm{Hf}$ were measured free from isobaric interferences. ${ }^{175} \mathrm{Lu}$ and ${ }^{178} \mathrm{Hf}$ were measured as proxies for ${ }^{176} \mathrm{Lu}$ and ${ }^{177} \mathrm{Hf}$, respectively. The resulting isotopic ratios of ${ }^{176} \mathrm{Hf} /{ }^{177} \mathrm{Hf}$ and ${ }^{176} \mathrm{Lu} /{ }^{177} \mathrm{Hf}$ were used to compute Lu-Hf ages. The technological innovation, involving two radiometric clocks, enables the ability to rapidly obtain age information for a large range of pallasite (and potentially other rocky meteorite) samples, with an aim to enhance our understanding of the early evolution of the solar system. 